\title{
Project-based Approach in a First-Year Engineering Course to Promote Project Management and Sustainable Energy Development
}

\author{
Pooya Taheri* (ptaherig@sfu.ca) and Csilla Tamás** (ctamas@langara.ca) \\ *Simon Fraser University, Surrey, BC, Canada \\ ** Langara College, Vancouver, BC, Canada
}

To safeguard the environment and satisfy the energy needs of the present, without compromising the ability of future generations to do the same, sustainable energy development is urgently needed [1]. This complex task is riddled with social, political, scientific, technical, and environmental challenges. Education is essential if we are to meet the energy demands of the world in the most sustainable manner available to us. Langara College offers a first-year engineering course that is meant to introduce students to engineering design and case studies, in addition to providing a brief glance on the history, ethics, and the different disciplines of engineering (APSC 1010-Engineering and Technology in Society [2]). This paper demonstrates how this, or similar courses are optimized to raise awareness of the sustainability issues this planet is facing.

Using a project-based learning approach that promotes teamwork and research, this course uses a variety of instructional methods including lectures, class discussions, and guest appearances by experts in their fields. Introductions to technical concepts, such as soldering, 3D printing, and microcontroller, are also addressed. The course culminates in a group project in which students are encouraged to select and research an issue on sustainable development. Several topics, which has already been briefly covered by the curriculum, include population, ecosystem, energy, and water.

Basic techniques of project and time management are integrated into formal lectures and class activities to prepare students for their group project in APSC 1010. In the first three weeks, students create groups of three to five and are tasked with choosing an engineering project that involves both research and a hands-on component. To pass the project, groups must submit a proposal, biweekly progress reports, a final report, a poster, and be subject to peer evaluation through final presentations.

In addition to the presentation required of the group project, each student must give an individual presentation on a technical topic of interest throughout the term. To prepare students for this assignment, one week of course time is devoted to the process of doing academic research. Students are introduced to the literature review, technical research procedures, and scientific reasoning.

The last four weeks are devoted to the group project. For the hands-on portion, students are free to make use of the institution's Makerspace, which is workshop equipped with 3D printers, a CNC router, laser cutters, scanners, sewing machines, and a selection of tools [3]. In this phase, based on the student's topic of choice, students learn about 3D design simulation, 3D printing, basic circuitry, electric motors, microcontroller programming, soldering, and woodwork.

A list of student projects is presented in this paper. Learning outcomes are evaluated using an anonymous student survey which demonstrates how the students' project-management and presentation skills have improved as a result of this course.

[1] T. L. Theis and J. H. Tomkin. Sustainability: A comprehensive foundation, 2012. Retrieved on Feb. 1, 2018, Online: http://cnx.org/content/col11325/latest/.

[2] APSC 1010 course description, Langara College, Retrieved on Feb. 1, 2018, Online: https://langara.ca/programsand-courses/courses/APSC/1010.html

[3] Langara College Makerspace, Retrieved on Feb. 1, 2018, Online: https://langara.ca/campusfacilities/makerspace/index.html 